\title{
Establishment of an economic evaluation model for urban recycled water
}

\author{
A. Listowski, H.H. Ngo*, W.S. Guo \\ School of Civil and Environmental Engineering, University of Technology Sydney, Broadway, PO Box 123, NSW 2007, Australia
}

\author{
Keywords: Economic assessment model; Urban recycled water; Productivity; Efficiency \\ Reliability
}

Abstract

This study aimed at establishing an economic evaluation model to encourage continuing improvement in performance analysis and applying for any infrastructure system of urban recycled water. A thorough study towards characterization and economic performance assessment of urban water reuse scheme were carried out. An integrated evaluation technique was developed by synthesizing the quantitative and qualitative performance indicators related to the water recycled technology and urban water cycle sys- tem. Specific performance indicators and indexes were aggregated into an economic analytical modelling for effective evaluation of the water reuse scheme and technology using uniform economic performance standards. Detailed economic analyses were successfully applied to enable determination of economic lifetime of the technology and the whole water reuse scheme. This research confirmed that productivity, efficiency and reliability measurements and factors could be successfully deployed for determining the scheme performance during various life cycle stages (e.g. design development, operational and functional verification, or comparison with other reuse projects). The economic assessment model was applied to improve uniformity of analytical process and performance measure. This article demonstrates benefits associated with the application of a standardized methodology for performing economic assessment and by maintaining strong correlation between multiparameter approach and adopted performance criteria in terms of productivity, efficiency and reliability. However, to ensure effectiveness of this assessment, the process would require systematic and perpetual inventory of the scheme performance data, consideration of variable factors such as capital and recurrent costs.

\section{Introduction}

Developing reliable and uniform measures of performance is a major challenge facing any public and private. In the continuously changing landscape of a broad range of recycled water technologies, environmental requirements, economic constraints and social concerns, it is evident that current assessment techniques must demonstrate its relevance and value to stakeholders. The demand for comprehensive performance assessment is part of a worldwide demand for more accountability for decisions that may have a long term impact on community, economy or environment.

The purpose of the economic evaluation of recycled water projects is to provide the economic rationale and robust evidence base that will underpin strategic and informed decision-making. Economic viability of water reclamation projects is strongly linked with the sustainability effects enduring throughout the life of the project. The underlying foundation for economic assessment of recycled water technology performance stems from the relatively weak argument that the costs of converting wastewater to useable high quality water supply are often shown as prohibitive when

\footnotetext{
* Corresponding author. Tel.: +61 2 95142745; fax: +61 295142633. E-mail address: h.ngo@uts.edu.au (H.H. Ngo).
}

compared with drinking water supply. In addition, there is an ongoing controversy over the net environmental and economic benefits of recycling water over its production costs. The latter is probably resulting from applying questionable assessment criteria, or a lack of agreement on tangible social, economic or environmental impacts as well as difficulties with quantification of externalities.

It is understandable, why in many cases of the implementation of recycled water scheme becomes problematic, particularly when capital funding and operating costs are compared with traditional potable water supply. This scenario is further distorted by the perception that recycled water is seen as a competition product to monopolized potable water services and a revenue loss by water utility company. Similar impasse exists in relation to a strong reluctance in awarding due credit for sewer mining associated with the water reclamation process. The economic challenges for implementation of recycled water schemes can be further characterized and grouped in the following areas: (i) high costs (capital and operation), (ii) unavailable or inadequate incentives associate with conservation of water resources and pollution reduction, (iii) no reward for avoided headwords, (iv) relatively long term investment return, and (v) limited level of revenue from recycled water services.

One of the major difficulties faced during economic performance assessment is acute lack of strong cost measures, a clear 
definition of input and output boundaries and reliable data pertaining to those inputs/outputs. Understandably, in most cases, the financial information is protected and confidentiality provisions usually protect it. Davenport (2009) suggested development of the economic performance tools could involve quantitative analytical method of measuring, monitoring and predict technology performance. This method should most certainly rely on applying of analytical tools, metrics and both financial and non-financial indicators. The evaluation methodology developed during this research addressed these challenges by setting up an integrated model that involves financial and economic assessment techniques. A key advantage of this model rests in systematic structure, standardization and logical step-by step evaluation process using sound economic principles.

The relationship between productivity, efficiency and reliability factors as well as life cycle costing assessment raise questions about technology performance, worth and value. It is clear that a single right or wrong solution does not exist for determining costs, occurrences and reasons. In fact several methods can be used to describe performance outcomes. There are no standards or formal certification method for economic assessment of water reclamation scheme. While there are examples and definitions of economic results, its value for comparison between even similar projects could be distorted and difficult to interpret.

The most certain advantage of the benchmark model developed in this study is that it does not require knowledge of professional modellers to carry out project economic analysis. It is necessary though to apply required quality input, understanding and precision in accordance with the following steps in the modelling process:

- Definition of project objectives, scope, concept, technology capability;

- Quantification of basic input technical and economic parameters;

- Input data information into base model;

- Calibration, validation and testing; and

- Simulation and sensitivity evaluation.

The economic evaluation model developed in this study is regarded as a necessary step towards unification and standardization of analysis and results to enable better or at least improved decision-making. The methodology that was developed for this purpose incorporates analytical tools and methods that have the potential to capture economic consequences of water reclamation on urban water cycle.

\section{Three pillars of performance assessment}

In order to understand important features describing the performance of recycled water scheme, it is necessary to take a broader view of its purpose, relevance, functionality, integrity, diversification, outcomes, achievement, and to reach consensus between competing disciplines without causing imbalance or tensions. A thorough review of the key technical, operational, financial, economic, social and environmental factors resulted in highlighting three most prominent pillars of sustainable assessment relevant to recycled water scheme and technology. These performance pillars are: productivity, efficiency and reliability (Fig. 1). The decision to adopt these criteria extends beyond traditional production or manufacturing. It encompasses resources, technologies, skills, efforts, fundamental business processes, functions and dynamics of decision-making.

Each pillar has its own description of purpose and its relevance in delivering expected outcomes. Furthermore, these three pillars do not just describe degree of excellence or a broad impact of the

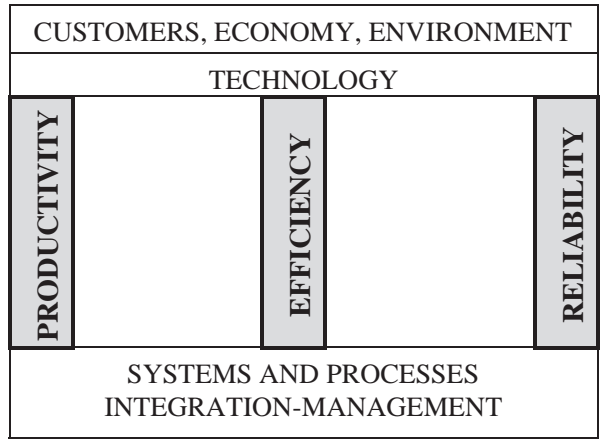

Fig. 1. Three pillars of performance assessment.

current performance, but facilitate opportunity for the continuous benefits and improvements. The current fragmentation existed in the performance assessment of water recycled schemes create a degree of uncertainty and unnecessary tensions, mainly because social and environmental benefits are often turned down, while the main focus remains on technical and economic interests. The three pillars performance assessment model allows conducting detailed analyses of the costs, benefits, risk and rewards. As a result of this approach, there would be greater opportunities to apply multiple objectives simultaneously and to assess the water cycle as a holistic system.

\section{Development of the productivity model}

\subsection{Principles of economic productivity for recycled water}

Productivity is a measure that indicates how resources are converted into the products and it can be expressed as partial, multifactor and total measures. There are other products that are linked with production process, such as waste streams. However, these could be examined independently under environmental assessment.

Economic productivity represents the value of output produced by the selected technology (Piana, 2001). Economic productivity accounts usually for multiple input/output and tangible factors involving costs of materials, equipment and labour. Nowadays, water reclamation technologies are significantly automated and integrated. Thus, it is difficult to justify any measurement as an individual productivity factors, particularly when many inputs are join into one product. The proposed method in this study was to aggregate these individual elements into a single total productivity index. Process productive utilization could be also defined as the ratio of time spent on productive efforts to the total time consumed.

\subsection{Productivity model}

The objective of developing productivity model for recycled water is to analyse changes (growth or diminution) in the performance of the scheme. It requires consideration of critical production inputs and the outputs and the relative correlations corresponding with the real scheme operation. A simplified profit and loss statement is often used for a snap shot illustration and modelling. Even as reduced, it comprises of a real measuring situation and most importantly the change in the output-input mix between two periods without any features of a real measuring situation being lost (Saari, 2006). In practice, there may be several products, inputs and outputs involved, but the logic of measuring does not differ from that presented in this study. In adopting a life cycle cost (LCC) approach to productivity measurement, emphases are on return on investment with particular attention focused on 


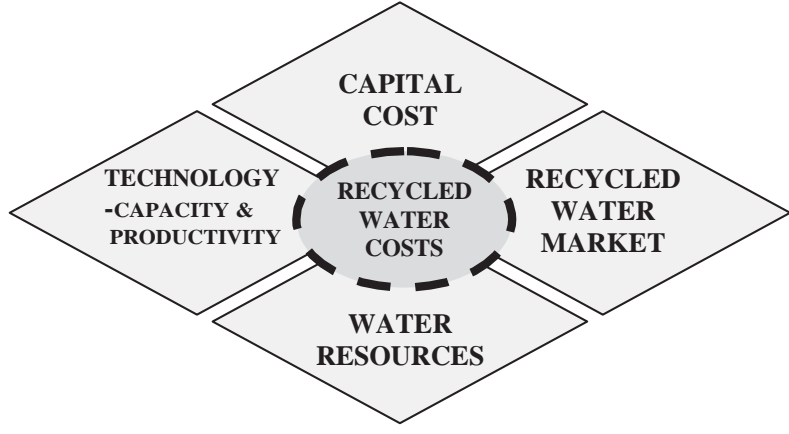

Fig. 2. Drivers of recycled water productivity.

five measures: (i) capital costs, (ii) treatment capacity, (iii) technology utilization rate; (iv) water resources and market, and (v) recycled water unit costs and market (see Fig. 2).

Although it is generally understood that increased productivity is economically advantageous, the concept of productivity growth could present some difficult to clearly define. It stems from the amount of output that can be produced from a given amount of input. Therefore, productivity growth should result in an increase of an output that can be produced for a given level of input or a decrease in the input (and potentially cost) required to achieve expected amount of output. In this sense productivity growth is desirable; the efficiency of production has increased so more g oods can be obtained given available scarce resources. The rela- tion between the above elements can be shown in the following formula:

$P=\frac{\text { profit }}{\text { total investment }} \times \frac{\text { revenue-costs }}{\text { output }} \times \frac{\text { output }}{\text { capacity }}$

where recycled water cost $=$ (capital recovery costs + O\&M costs)/productivity of recycle water plant in $\mathrm{kL} / \mathrm{y}$ ); capital recovery = debt and equity cost; and O\&M cost $=$ total LCC.

The above equation illustrates that any changes in the rate of return on investment is influenced by interactions between recycled water production costs, price, the rate of process capacity utilization, and the total capital input in creation production capacity.

The productivity is closely linked with the process of economic growth associated with the changes in output/input relation and consequential increase in productivity. Surplus value of productivity refers to the difference between income and costs indicating higher value than costs of production.

Table 1 shows the calculation model of productivity that is applicable to Water Reclamation and Management Scheme, which has been operating for over 10 years (Listowski, 2005, 2006). The time factor and established performance standards play important role in defining productivity. One of the gross misconceptions about productivity is that it is driven by labour productivity. This statement is based on traditional assumption that labour input is critical and it could be easily quantified factor of production. Essentially, the observations and data obtained during this research confirm that although labour has its important role, several technological elements play crucial role in achieving productivity growth and increasing output without major labour influence and increase in costs.

Table 1 provides practical illustration of productivity measurement over one year period. As to the productivity index can be calculated for any specific period of time, this model could be applied to encompass any timescale. It was applied to analyse annual changes in the level of economic performance in such a way as to assess the relative influence of the productive effects and the market effects for a specific period. The productivity calculation process can be explained in following steps:

- Quantification of production of recycled water (or any other products);

- Quantification of all input costs;

- Calculation of the impacts of the income distribution process;

- Calculation of the production process on the profitability of the scheme.

The index reflects a change in quantity of input factors namely the amount of capital and resources used in the production process. The total income and costs calculations are necessary for understanding the concept of a surplus value. This value was based on the accumulated quantities and fixed prices for the assessment year.

\section{Development of economic efficiency model}

\subsection{Economic efficiency of water reclamation}

Economic efficiency is a term typically used in economics when discussing a relation between resources, production and the costs. Efficiency performance both in technical and economic terms favours recycled water as reuse directly contributes to increase of the water supply and also eliminates wastage of already treated sewage effluent that when discharged to receiving waters causes further environmental degradation. Technological efficiency occurs when it is not possible to increase output without increasing inputs, thus production is considered cost efficient if no more can be produced for the same or less cost.

Economic efficiency occurs when the cost of producing recycled water is as low as possible, but it is only relevant when the quality of water being produced remains unchanged. The economic efficiency is different from technical efficiency, which seeks to achieve the maximum production from the given amount of input used to produce it. Technological efficiency is important precursor to cost and economic efficiency. Economic efficiency analysis counts benefits and costs. Other economic measures such as income, wages and salaries, value of output, or employment should not be included in such analysis (Mann, 2008).

This study considers key actions and issues related to the economic efficiency of recycled water scheme and technology that can be reasonably quantified and evaluated. Water pricing is central to economic efficiency. In conventional economic theory, efficient pricing is closely dependent on the cost structure. Efficient water use requires that the price to end users equals the marginal cost of providing that increment of supply. The price should include the variable costs related to generating that unit of water supply.

\subsection{Efficiency assessment framework}

Economic efficiency of the water reclamation scheme and technology could be best calculated using the following indicators and its relationships:

- Capital investment costs defined at the end of construction period;

- Annual capital, maintenance and operating costs per volume of produced water; and

- Annual energy costs per volume of produced water.

One of the pressing issues with efficiency analysis is the question of decision between increased costs associated with additional performance improvement. When it comes to making investment decision, often the greater drive is towards lowering costs and 
Table 1

Water reclamation productivity model.

\begin{tabular}{|c|c|c|c|c|}
\hline & \multicolumn{4}{|l|}{ Year 2009} \\
\hline & Production quantity (kL) & Unit price $(\$)$ & Production value $(\$)$ & Surplus value (profitability) \\
\hline \multicolumn{5}{|l|}{ Output (annual) } \\
\hline Recycled water & 702,455 & 1.72 & $1,208,223$ & $1,306,566$ \\
\hline Other products & 0 & 0.00 & 0 & 0 \\
\hline Total output & & & $1,208,223$ & $1,306,566$ \\
\hline \multicolumn{5}{|l|}{ Input (annual costs) } \\
\hline Fixed O\&M cost & 1 & $245,854.00$ & 245,854 & 252,000 \\
\hline Variable $0 \& M$ costs & 1 & $467,633.00$ & 467,633 & 479,324 \\
\hline Distribution system O\&M & 1 & $11,707.00$ & 11,707 & 12,000 \\
\hline Energy cost & 1 & $221,772.00$ & 221,772 & 227,316 \\
\hline Miscellaneous cost & 1 & $146,342.00$ & 146,342 & 150,000 \\
\hline Capital & 1 & 150,000 & 150,000 & 150,000 \\
\hline Total input & & & $1,243,308$ & $1,270,640$ \\
\hline Surplus value & & & $-35,085$ & 35,926 \\
\hline Surplus value index & & & 0.972 & \\
\hline Change in distribution & & & & 71,012 \\
\hline Distribution index of output & & & 1.081 & \\
\hline Distribution index of input & & & & 1.022 \\
\hline Distribution index & & & & 1.104 \\
\hline Productivity index & & For year 1 & & 1.028 \\
\hline
\end{tabular}

finding c heaper technological solution. This situation could also be improved by incremental production increase to gain greater economies of scale, which could be realistically achievable with the water reclamation scheme. In this situation cost efficiency analysis should involve:

- identification of two or more alternatives,

- quantification and key parameters of the project/process/production,

- appraisal of costs and the values, and

- comparison of options.

Efficiency analysis could be initially simplified by applying the Cost-Efficiency Pane (Fig. 3). This is a graphical representation of the incremental changes in total cost ( $y$-axis) and effect of productive efficiency of water reclamation scheme (x-axis) by showing dependency between various alternative comprising of products, services and production activities as a function of costs (capital, maintenance and operational).

The analysis results place cost-effectiveness relations into one of the four following cost-effectiveness quadrants and ranking:

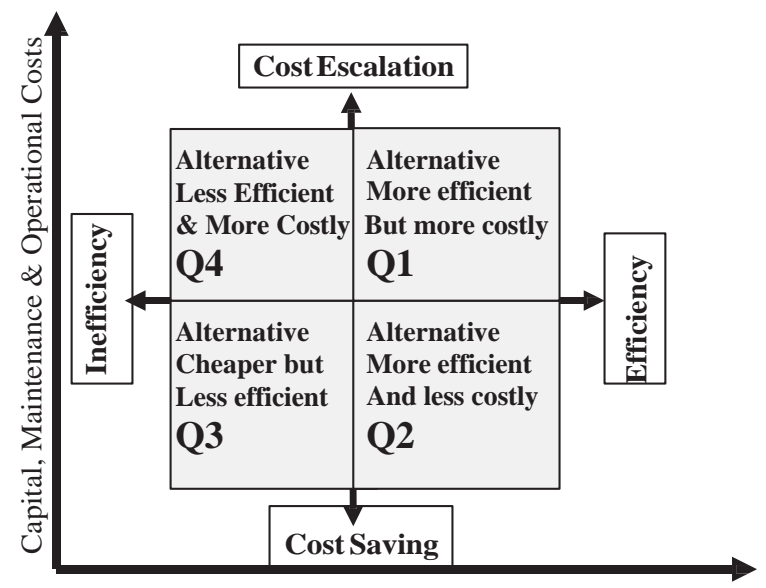

Products, services \&production activities

Fig. 3. Four quadrants of the relation between costs and efficiency.
Q1. Increased cost, increased efficiency: Although this appears to be the most desirable solution, further analysis is needed to justify whether the additional efficiency gain is worth the increased cost. The pressing issue with this scenario is the cost. One way to make this an easier investment decision is by finding ways to lower the cost by using for instance cheaper technology. Another way to balance the cost would be to increase recycled water customer base, increase production in order to make use of greater economies of scale.

Q2. Reduced cost, increased efficiency: The project may be deemed beneficial or not based on the net result of cost and efficiency increase. Further analysis is needed to clarify the result.

Q3. Reduced cost, reduced efficiency: Although some cost benefits occur, decline in efficiency is not acceptable. This could be the case of promoting costs savings and inefficient use of technology.

Q4. Increased cost, reduced efficiency: Investments falling into this quadrant are worse in terms of cost, as well as in terms of effectiveness and are not economically beneficial.

It is important to realize that further conclusions can be drawn from the examination of above quadrant borders, whereby either the cost stays constant and effectiveness increases, or the cost decreases and effectiveness remains the same and efficiency and costs benefits are positively correlated with each other.

\subsection{Economic efficiency model}

Efficiency is a relative category and the calculation based on using a single formula may not be enough to declare whether treatment process is efficient or not. Economic efficiency is discussed exclusively as the measurable and quantifiable result of input resources, activities and costs. The cost efficiency measure for recycled water production is defined as a function of the annualized total capital investment and annual operating costs divided by the annual recycled water production measured in $\mathrm{kL}$. The equation used to calculate cost-efficiency is as follows:

$\mathrm{EFF}_{\mathrm{Co}}=\frac{\mathrm{Co}+\mathrm{C}_{\mathrm{M} \& \mathrm{O}}}{\mathrm{Q}_{\mathrm{RW}}}$

where $\quad \mathrm{EFF}_{\mathrm{Co}}=$ cost efficiency index; $\mathrm{Co}=$ capital costs; $\mathrm{C}_{\mathrm{M} \& \mathrm{O}}=$ maintenance and operating cost; and $\mathrm{QRW}_{\mathrm{RW}}=$ recycled water production. 
The sensitivity analysis would demonstrate dependency between capital costs, M\&O costs and production, which in this case are expressed as efficiency index (EI).

Capital cost has lesser impact on EI because its influence on production, maintenance and operating costs is also lesser. High capital costs could also result from a procurement process, pursuit of technological innovations, obtaining fairly new or emerging technology rather than the one that is well established in the market place.

The primary tool for conducting economic efficiency is the CostBenefit Analysis (CBA) method. Recycled water projects not only involve new and replacement capital expenditure, infrastructure, buildings and equipment but also human resources, materials and energy that are necessary for production. These elements should be subjected to analysis of their costs and benefits over their lifetime.

CBA utilizes Discounted Cash Flow (DCF) analysis which is based on predetermined discount rates over the project life time. The CBA is calculated using the following formula:

$$
\begin{aligned}
& \mathrm{CBA}=\frac{\mathrm{NPV}_{\mathrm{B}}}{\mathrm{NPV}_{\mathrm{C}}} \\
& \mathrm{NPV}=\sum_{0}^{t} \frac{B_{t}-C_{t}}{(1+r)^{t}}
\end{aligned}
$$

where $\mathrm{NPV}_{\mathrm{B}}$ - net present value of benefits; $\mathrm{NPV}_{\mathrm{C}}$ - net present value of costs; $B_{t}-$ benefit at time $t ; C_{t}-\cos t$ at time $t$; and $r-$ discount rate.

The main reasons for selecting CBA as preferred method are: (i) enables to evaluate projects on an equal basis irrespective of their size; (ii) allows the planners to take a long view of project lifetime; and (iii) yields a ranking of projects which, for all practical purposes, proves to be quite scientific and satisfactory.

The costs benefit assessment is sub ject to a range of variables that could have some affect on the accuracy of an outcome. This sit- uation is typical to almost any evaluation methods. To ameliorate precision of this process it would be necessary to include critical assumptions and to carry out sensitivity analysis. The key assump- tions include: (i) the initial capital costs, periodic major upgrades, costs of materials, energy and labour are subject to market fluctu- ations and (ii) discount rate that affects NPV analysis and its life cycle costs.

There are some important rules that should apply to CBA methodology for assessment of recycled water schemes and must take into account:

- The benefits to costs ratio should be greater than 1 (one) and shows there is net cost benefit to a particular project and that the benefits exceed the associated costs.

- NPV calculation is the preferred method because it is understandable and easy to apply. The net NPV sum of a proposal must be greater than zero. There are, however, other common rules in addition.

- CBA is conducted on a cash accounting basis. The full cash cost of capital is considered in the analysis at the time of purchase so that over the life of the project the item can be depreciated in full.

- Depreciation is a non-cash expense (cost) and should not be included in a CBA. To do so would be a form of double counting because the full cost is allowed for at the time of purchase.

- Interest payments are also excluded from the cash flow in CBA because they are implicitly reflected in the process of discounting (Commonwealth of Australia, 2006).

Economic efficiency of the water reclamation is directly related to changes in management and operation of traditional potable water supply and wastewater and stormwater services. In measuring the net change and potential savings it is necessary to realize: (i) current and future infrastructure capacity savings, (ii) reduction in collection, transportation, treatment and disposal of wastewater; (iii) reduction in load based costs associated with effluent disposal to environment, and (vi) deferral of various augmentation costs (new sewage treatment, potable water headworks, infrastructure distribution systems).

All these scenarios could be analysed using two-step process that incorporates avoided costs and costs recovery in relation to water and sewerage expenditure. The methodology for calculating costs offsets or avoided costs (AC) and is based on establishing the total costs for water and sewage demand first and then deducting total permanent impact associated with recycled water scheme and appropriate costs deductions from the total costs of meeting these demands. For this purpose, it is necessary to confirm the following assumptions and principles:

- Present value (PV) include current and future capital and operating costs resulting from recycled water scheme.

- Present value (PV) include current and future capital and operating cots resulting from potable water and sewerage services with and without recycled water.

- PV calculations should be consistent and based on similar planning assumptions e.g., demand projections, demographic growth, climate changes, performance standards, etc.

- Time period for calculation of capital and operating costs is 30 years.

- Discount rate on existing assets - 4\% (adopted rate needs to verified).

In support of the above methodology the following IPART (2006) formula was applied:

$$
\begin{aligned}
\mathrm{AC}= & \mathrm{NPV}_{\mathrm{r}}\left[\mathrm{K}(\mathrm{o})_{\mathrm{i}}+\mathrm{OC}(\mathrm{o})_{\mathrm{i}}-\mathrm{K}(\mathrm{w})_{\mathrm{i}}\right. \\
& \left.+\mathrm{OC}(\mathrm{w})_{\mathrm{i}}\right] \text { for } \mathrm{i} \text { years } 1, \ldots, \mathrm{n}, \quad \mathrm{n} \leq 30
\end{aligned}
$$

where $\mathrm{AC}=$ avoided costs; $\mathrm{NPV}_{\mathrm{r}}=$ the net present value discounted at rate $r ; r=$ discount rate; $K(0)=$ the forecast capital expenditure for year (i) without recycled water scheme; $\mathrm{K}(\mathrm{w})=$ the forecast capital expenditure for year (i) with recycled water scheme; OC(o) = the forecast maintenance and operating expenditure for year (i) without recycled water scheme; and $\mathrm{OC}(\mathrm{w})=$ the forecast maintenance and operating expenditure for year (i) with recycled water scheme.

In this scenario, operating costs are based on the estimated annual expenditure including allowable increases such as price escalation, Consumer Price Index (CPI). Cost recovery needs to apply to both capital and operating expenditure. There are two possible sources of costs recovery: one from customers, and two from water utility company.

An important point in the discussion of applying avoided cost methods to value conserved water is the proper definition of marginal costs. Marginal costs refer to the cost of producing (or not producing) another unit of water supply. In estimating marginal costs, a central issue is where the next increment of supply will come from and what it will cost. Two important components of marginal cost are changed in operating costs caused by a change in the use of existing capacity (short-run marginal operating cost), and cost of expanding capacity (long-run marginal capacity cost).

Short-run marginal costs are comprised mostly of variable operating costs. Long-run marginal capacity costs extend to time periods far enough into the future to be changed by system and resources planning. Long-run marginal costing methods can identify costs that can be avoided through more efficient use or non-use e.g. water conservation (CUWCC, 2006).

Economic standards should be set on the condition where marginal benefits equal marginal abatement costs. In terms of incentive effects the problem with standards is that when they are 
being met there is no incentive to do better than the standards. Using a financial model, wastewater treatment to levels acceptable for return to the river is expensive in terms of the direct financial cost of installing and operating the required treatment processes and related infrastructure. At the same time, the anticipated revenue stream is relatively low. Revenue potential is low because water treated to reuse levels has limited markets and water returned to the river does not generate revenue. Thus, on a cash flow basis, treatment to reuse levels appears to be a financial loser.

\section{Reliability and economic performance analysis}

While reliability is an intuitively appealing concept, quantifying it can be challenging for both conceptual and logistical reasons. The ultimate goal of this study was to provide consistent framework, to refine and operationalize the concept of reliability in relation to recycled water scheme and technology. This clearly defines the sphere of influence and key considerations that must be accounted for in the reliability indicators and metrics that are ultimately developed and practically applied.

Recycled water supply reliability has become an expected feature of all modern urban recycled water schemes. Nevertheless, recycled water systems fail and they do so for any number of reasons, including design, natural causes or human errors. Reliability is conceptually related to the probability of system failure, and the rate, occurrence, and consequences of failure can be measured in several ways, depending on the needs and relevance of the particular situation. It depends on the complex interactions between technology, water quality, scale of operation, complexity and water distribution system.

For this reason it is necessary to examine operations functions that are particularly concerned with having necessary indicators that measure reliability and focus on the following aspects:

- Type of service: clear definitions of the technology, specific servicing requirements, quantity, quality and any delivery limitations;

- Temporal scale of assessment;

- Physical and Economic Indicators that describe the costs associated with reliability and those physically based indicators change.

Reliability issues are challenged on two major fronts. The first is the process design, technology and equipment, which are vital elements contributing to inherent reliability and total life cycle cost. The other aspects relates to management and operation if the equipment over the project life time. However, maintenance management policy that maximizes the availability/performance will not necessarily maximize the reliability of a system.

\subsection{Reliability assessment methodology}

The economic issue of the reliability is to control the costs arising from unreliable technology or process failure. Usually, process failures or downtime stoppage mean a loss of production and reduced efficiency. The field of reliability assessment offers many guidelines for how data should be interpreted and analysed, but the lack of process data mostly affects this process, mainly because failures are not always documented or clearly quantified. Technical reliability is better understood when expressed in economic terms as a loss of time and money or cost of unreliability, cost of improvements or increased annual profit.

Improving reliability means always an increased capital cost that brings an expectation for improving plant availability, reduced downtime and potentially lower maintenance costs, thus better opportunity for making profit. While general calculations of reliability pertain to constant failure rates, the following terms can describe reliability in quantitative words; mean time to failure, mean time between failures, mean time between/before maintenance actions, mean time between/before repairs, mean life of units in counting units such as hours or cycles, failure rates, and the maximum number of failures in a specified time interval (Barringer, 1997).

Water authorities now take a commercial view of recycled water services and customers that are paying tariffs for recycled water have high expectations from their recycled water service. Consequently, high operational standards are required to meet these customers' expectations including: (i) reliable production of quality recycled water; (ii) clear rules for sharing recycled water; and (iii) infrastructure that can distribute the water at the required flow and pressure (Wallis, 2009).

Usually recycled water providers choose to go beyond required quality standards and produce a much higher quality of water. Reliability assessment from water quality criteria point of view has the following trigger points:

- Short term value - a value where parameters exceed the required criteria in short term. Water quality sampling and analysis are usually performed on a weekly, fortnightly and monthly basis. The short term "failure" results do not constitute process failure, however continued short term value sample failures may result in a failure to comply with the annual value. The result of the short term sample is used to calculate the annual value.

- The annual value is the value which must be achieved by each parameter at each 12 monthly interval and calculated as $95 \%$ of the short term value sample results for the twelve month period. Example: During the year, weekly sampling is required providing 52 test results and 95\% required compliance standard it equals to 49.4 or $\sim 50$ short term sample results that must not exceed necessary limits.

The above criteria are necessary for classification of incidents related to recycled water quality on equal basis with mechanical, electrical or process failures and should be used for quantitative assessment of recycled water process reliability index. Reliability also deals with reducing frequency of failures over a given time period, which is regarded as a long mean time between failures.

\subsection{Economic reliability analysis}

Reliability and economics are inextricably linked over an entire water reclamation project life cycle from the initial system design through implementation and operation. Many plants are now being designed with strong emphasis on minimizing risks of failures such as process, mechanical and electrical equipment by having installation in redundant arrays. The redundancy seldom shuts down operation, but it might cause losses in production or high replacement costs.

Reliability analysis and life-cycle costing are used to assess the performance of the water reclamation technology over time and also to assess the total costs of various management strategies that could improve performance and reduce risks of failure at least cost. An important aspect in conducting these analyses is to maintain consistent approach in the way costing tools are applied. There are two important principles: (i) the time value of money and (ii) decision, which costs are included/excluded.

Time value of money issue is related to the real value of money changes over time and it can be satisfactorily resolved by adopting concept of Discounted Cash Flow (DCF). In practical sense, this approach should allow the decision maker to differentiate between a more reliable system might cost more up front, but may cost less over time if the whole life cycle is taken into account. 
Table 2

Water reclamation plant MTBF, failure rate and time losses.

\begin{tabular}{|c|c|c|c|c|c|}
\hline & \multicolumn{3}{|c|}{ Water reclamation plant } & \multirow[b]{2}{*}{$\begin{array}{c}\text { ANNUAL } \\
\text { SUMMARY }\end{array}$} & \\
\hline & \begin{tabular}{c|} 
PROCESS \\
CONTROL \\
POINT - \\
MODULE A
\end{tabular} & $\begin{array}{c}\text { PROCESS } \\
\text { CONTROL } \\
\text { POINT - } \\
\text { MODULE B }\end{array}$ & $\begin{array}{c}\text { PROCESS } \\
\text { CONTROL } \\
\text { POINT - } \\
\text { MODULE C }\end{array}$ & & \\
\hline Observation period (h & 43800 & 26280 & 35040 & 8760 & (h/year) \\
\hline Number of failures & 3 & 1 & 5 & 2.18 & (fail./year) \\
\hline MTBF & 14600 & 26280 & 7008 & 4018 & (hrs/fail) \\
\hline Failure rate & $6.85 \mathrm{E}-05+$ & $3.81 \mathrm{E}-05+$ & $1.43 \mathrm{E}-04=$ & 2.49E-04 & (fail./h) \\
\hline Failure per year & 0.6 & 0.33 & 1.25 & 2.18 & (fail./year) \\
\hline Corrective time & 54 & 18 & 102 & 76.1 & (h/fail) \\
\hline Lost time $(\mathrm{h} / \mathrm{y})$ & $32.4+$ & $5.94+$ & $127.5=$ & 165.84 & (h/year) \\
\hline
\end{tabular}

The second factor that influences reliability analysis is related to cost consideration and decision about what costs shall be included or exclude from analysis. Making clear distinction, which costs are related to treatment process reliability and used in a costing analysis is very important. The adopted rule is based on the least costs approach. This means assessment horizon is narrowed to direct costs only as a cut-off point.

Such cost should be directly linked with the activity that generates the cost including time, labour and materials necessary to carry out repair of components identified as being critical to system performance. Reliability analyses could include direct consequential costs that are reasonably incurred by the failure. This approach has the potential to display accurate and complete costs for a particular technology and process operations.

Detailed analysis could be successfully applied to determination of economic lifetime of the technology (or the whole system), that is referred to as economic replacement analysis. It is recommended that this method should be considered in conjunction with the risk analysis, particularly when probability of failure is high, but the consequence is low. The potential for failure can be assessed through both technical reliability analysis and asset inventory analysis using the following formula:

Reliability index $\quad \mathrm{R}_{\mathrm{I}}=\frac{\text { unplanned capacity loss }}{\text { total capacity }} \times 100 \%$

and

Reliability index $R_{I}+$ unreliability index $R_{U}=1$

Reliability of the water reclamation scheme deals constantly with reducing incidents of unscheduled breakdowns and process failures over defined time interval. Product manufacturers measure reliability by completing a failure free warranty period under specified operating conditions. Statistical methods are applied to calculate specific reliability factors and it has been explained in previous sections.

In economic terms any effects of breakdown results in some degree production interruption, additional costs or other economic consequences. Improving reliability occurs at an increased capital cost but brings the expectation for improving availability, decreasing downtime and associated maintenance costs, improved secondary failure costs, and results in a better chance for making money because the equipment is free from failures.

Last 12 years of Water Reclamation and Management System (MRAMS) (Sydney Olympic Park, Australia) operation history was analysed to establish critical elements that would enable assessment of reliability and establishment of reliability factor, WRAMS plant failure rate could be expressed in an understandable form using defined time frame in each process module. Table 2 shows the summary of mean time between failures (MTBF), failure rate and time losses for typical water reclamation plant that consist of biological treatment, membrane filtration process and recycled water pumping system.

The above analysis indicated that (i) failures could occur at random at each module; (ii) impact from one module's failures is not necessary related to other modules; (iii) time duration is important factor in calculation of loss; (vi) correlation between time loss and loss of production loss might be essential factor in total unreliability estimates; and (v) it is important to use reasonable length of time for the reliability assessment and based on this research a period of up to 5 years is recommended as the most optimum.

Table 3

Water reclamation unreliability cost summary.

\begin{tabular}{|c|c|c|c|c|c|}
\hline & \multicolumn{3}{|c|}{ Water reclamation plant diagram } & \multirow[b]{2}{*}{$\begin{array}{l}\text { ECONOMIC } \\
\text { SUMMARY }\end{array}$} & \\
\hline & \begin{tabular}{|c|} 
PROCESS \\
CONTROL \\
POINT - \\
MODULE A
\end{tabular} & \begin{tabular}{c|} 
PROCESS \\
CONTROL \\
POINT - \\
MODULE B
\end{tabular} & \begin{tabular}{|c|} 
PROCESS \\
CONTROL \\
POINT - \\
MODULE C
\end{tabular} & & \\
\hline Lost time $(\mathrm{h} / \mathrm{y})$ & $32.4+$ & $5.94+$ & $127.5=$ & 165.84 & (h/year) \\
\hline Gross profit loss & $\$ 9,720$ & $\$ 1,782$ & $\$ 38,250$ & $\$ 49,752$ & $2(\$ /$ year $)$ \\
\hline Cost of repairs and plant restart & $\$ 16,200$ & $\$ 2,970$ & $\$ 63,750$ & $\$ 82,920$ & (\$/ year) \\
\hline Recycled water system recharge & 8,100 & 1,485 & 31,875 & 41,460 & (\$/ year) \\
\hline Total cost of unreliability & $\$ 34,020+$ & $\$ 6,237+$ & $\$ 133,875=$ & $\$ 174,132$ & (\$/ year) \\
\hline Treatment Plant Total Capacity & 850,000 & 850,000 & 850,000 & 850,000 & $\mathrm{~kL} / \mathrm{year}$ \\
\hline Unplaneed Capacity Loss & 3,144 & 576 & 12,372 & 16091.8 & $\mathrm{~kL} / \mathrm{year}$ \\
\hline Unreliability Index & 0.370 & 0.068 & 1.455 & 0.631 & $\%$ \\
\hline Reliability Index $\mathrm{R}_{1}$ & 99.630 & 99.932 & 98.545 & 99.4 & $\%$ \\
\hline
\end{tabular}


Table 4

An integrated Economic Life Cycle Assessment process.

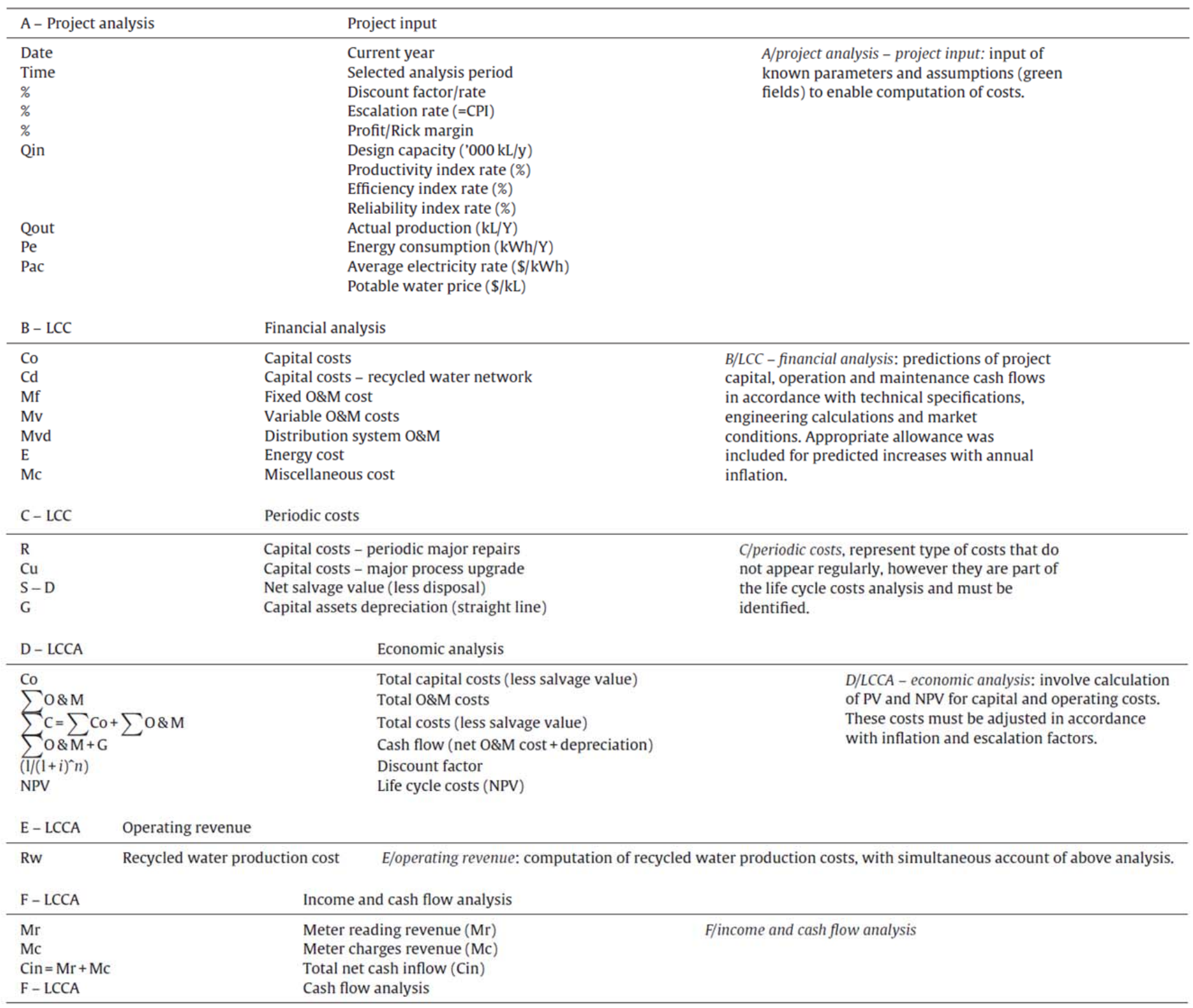

High reliability and process availability are important economic and social factors and Table 3 illustrates relatively high degree of treatment process reliability at $99.4 \%$ per annum.

Based on the failure time data it would be possible to calculate economic effects of process failure or economic costs of unreliability. For this purpose it is essential to make allowances for unit costs and hourly rates (examples based on Australian market) for:

- economic value of recycled water production - $\$ 300$ per hour (based on plant production of $4000 \mathrm{~m}^{3} /$ day),

- maintenance costs of $\$ 500$ per hour (fixing and/or replacing equipment), and

- recharging recycled water distribution system - \$250 per hour.

Recycled water treatment technology and scheme operation must display exceptionally high level of reliability at all the times. The acceptable range was determined as follows:

- Desired reliability index value (RI) is set at $100 \%$ measured per annum.
- Minimum reliability index (RI) is set at $95 \%$.

- Any reliability values below 95\% are unacceptable.

Any values $<95 \%$ means that approximately 18 days a year treatment process, plant, water quality standards, water supply parameters, operational safety, etc. could be compromised plant. Lower reliability implies higher level of public risk, frequent occurrence of failures, potentially high consequential costs, inadequate operational responsiveness, and possible deficiency in the process design and technology. The probability of process failure and interruption to recycled water supply is quite small. However, the impact on customer services could be quite dramatic and in fact the risk is quite analogical to potable water supply.

The reliability index calculation is a practical tool for converting risk or actual failure into costs. While these calculations are based on actual data, it is understood that accuracy of these indicators are improving. The above model could be further expanded to include many additional control points and data. When larger volume of data is available, this technique can prove to provide more precise results. Literature review confirmed that approximately $70 \%$ of 
reliability issues are influenced by process control and 30\% induced by mechanical failure (Rainhart, 2006).

\section{Summary of economic analysis in recycled water}

The knowledge included in the base model represents summary of analysis carried out above. It is aimed at supporting project during initial selection and decision-making period. It incorporates conceptual engineering assumptions, theoretical knowledge, specifications and operating data. As the question of performance is constantly arising during project life time, it is prudent to extend the basic model functionality to enable monitoring and reporting continuously. A customised version of the base model is shown in Table 4 and incorporates the key project characteristics.

\section{Conclusions}

This research paper presents a scientific methodology for ascertaining performance of water reclamation scheme and technology. Econometric models include productivity, efficiency and reliability have been developed and applied through the application of actual performance data values to econometric analysis. This method has an advantage over fragmented and circumstantial factors used in financial analysis as it has capability to provide an accurate performance characteristic and to express this in a life cycle economic terms. Performance trends were developed, along with the relative factors and calculations to improve forming predictions and expectations.

Variable elements such as technology and production performance costs, revenue, discount rates, scheme duration, fixed and variable costs found to have significantly impact on the assessment outcome. Data values for these variables and the calculated costs function have been obtained from an actual scheme operation. Outputs coefficients can be further developed and illustrated in a number of ways, i.e. number of customers, characterization of users, diurnal and seasonal demand valuations, development of benchmark characterization and industry standards in relation to economic returns, scheme returns scale of economics.

\section{Acknowledgements}

The authors wish to acknowledge the support of the Sydney Olympic Park Authority and United Group Limited in providing information necessary for the preparation of this manuscript.

\section{References}

Barringer PH. Availability, reliability, maintainability and capability. Triplex Chapter of the Vibrations Institute. Humble, TX: Barringer and Associated Inc.; 1997 [accessed 24.05.10].

Commonwealth of Australia. Introduction to cost-benefit analysis and alternative evaluationmethodologies; January 2006.

CUWCC - The California Urban Water Conservation Council. Water utility direct avoided costs from water use efficiency; 2006.

Davenport TH. The rise of analytical performance management. Harvard Business Digital. SAS Institute Inc; 2009.

IPART. Pricing arrangements for recycled water and sewer mining services. Determination No's 8 \& 9, 2006. Independent pricing and regulatory tribunal; 2006. ISBN: 1-920987-79-7.

Listowski A. Recycled water system for future urban development. Paper presented at Membrane and desalination specialty conference in Adelaide, 2005; 2005.

Listowski A. Water for the future. Integrated Urban Water Cycle System at Sydney Olympic Park, SOPA; 2006.

Mann R. Economic efficiency of water use and allocation in California. Analysis; 2008. http://deltavision.ca.gov/BlueRibbonTaskForce/June2008/ [20.04.10].

Piana V. Productivity: a key concept in economics. Economics Web Institute; 2001 http://www.economicswebinstitute.org/glossary/prdctvt.htm [accessed 21.04.10].

Rainhart NF. A different perspective on plant reliability. Improved reliability control by improving process control. Presented at the 61st symposium for the process industries. TX: Department of Chemical Engineering, A\&M University; 2006.

Saari S. Productivity theory and measurement in business. Finland: Satakunta University of Applied Sciences; 2006 seppo.saari@samk.fi [accessed 06.04.10].

Wallis D. Reticulated recycled water schemes - operational considerations. In: 72nd annual water industry engineers and operators' conference; 2009. 